\title{
The Relationship between Spatial Ability and the Conservation of Matter in Middle School
}

\author{
Merryn Cole ${ }^{1, * \mathbb{D}}$, Jennifer Wilhelm ${ }^{2}$, Briana Marie-McKnight Vaught ${ }^{3}$, Corinne Fish ${ }^{4}$ and Hailey Fish ${ }^{5}$ \\ 1 Department of Teaching and Learning, University of Nevada, Las Vegas, NV 89154, USA \\ 2 Department of STEM Education, University of Kentucky, Lexington, MA 40506, USA; \\ jennifer.wilhelm@uky.edu \\ 3 Western High School, Clark County School District, Las Vegas, NV 89107, USA; \\ brianamarie.mcknight@gmail.com \\ 4 Reedsburg Area High School, Reedsburg Area School District, Reedsburg, WI 53959, USA; \\ corinne2donfish@gmail.com \\ 5 Middle School Science, Stonebridge World School, Minneapolis, MN 55419, USA; fish.hailey.j@gmail.com \\ * Correspondence: merryn.cole@unlv.edu
}

Citation: Cole, M.; Wilhelm, J.; Vaught, B.M.-M.; Fish, C.; Fish, H. The Relationship between Spatial Ability and the Conservation of Matter in Middle School. Educ. Sci. 2021, 11, 4. http:/ /dx.doi.org/10.3390/

educsci11010004

Received: 2 November 2020 Accepted: 21 December 2020 Published: 24 December 2020

Publisher's Note: MDPI stays neutral with regard to jurisdictional claims in published maps and institutional affiliations.

Copyright: (c) 2020 by the authors. Licensee MDPI, Basel, Switzerland. This article is an open access article distributed under the terms and conditions of the Creative Commons Attribution (CC BY) license (https: / creativecommons.org/ licenses/by/4.0/).

\begin{abstract}
Research has shown that spatial ability plays a key role in understanding STEM (Science, Technology, Engineering, and Mathematics) content, including chemistry. Conservation of Matter $(\mathrm{CoM})$ is an essential but challenging topic for chemistry students of all ages to grasp; it is often taught in a way where students memorize it but do not learn what it means conceptually. This research explored the relationship between understanding spatial ability and conceptual understanding of $\mathrm{CoM}$ in middle school students. CoM was examined in two ways using the Conservation of Matter Assessment (CoMA): through questions on conservation of atoms and the conservation of mass. Spatial ability was measured using the Purdue Spatial Visual Test: Rotations (PSVT). Significant, moderate correlations were found between spatial ability and understanding of CoM prior to and after a chemistry unit including instruction on $\mathrm{CoM}$; the correlation was stronger after instruction. Scores on the PSVT and CoMA significantly increased pre to post instruction. The data show spatial ability may impact students' understanding of $\mathrm{CoM}$, which contributes to the literature on factors that impact students' understanding of chemistry. Additionally, it provides evidence that teachers should consider including spatially rich experiences in their chemistry classroom, such as making explicit connections between the areas of Johnstone's Triad.
\end{abstract}

Keywords: chemistry; spatial ability; middle school; conservation of matter

\section{Introduction}

Students learn chemistry mostly through 2-D visualizations representing 3-D structures and chemistry concepts [1]. Students struggle to understand that atoms are neither created nor destroyed, instead rearranging themselves in chemical reactions [2]. In the United States Next Generation Science Standards (NGSS), the performance expectation MS-PS1-5 states that students must "develop and use a model to describe how the total number of atoms does not change in a chemical reaction and thus mass is conserved" [3]. As a result, they struggle to make meaningful connections from the representations of the particulate domain to observable natural phenomena, also called the macroscopic domain [4]. This ability to make the connection is important for understanding the fundamental concept of conservation of matter, which is introduced in middle school chemistry. Students hold many misconceptions about conservation of matter, and traditional teaching methods fail to address these misconceptions [5]. One reason is students' difficulty in connecting the macroscopic phenomena with which we can directly interact or observe with the particulate (or sub-microscopic) level where the chemistry is happening and communicating these ideas in the heavily symbolic language of chemistry $[6,7]$. How do we 
help students understand the complexities behind molecules and atoms, which is necessary to understanding conservation of matter? Enhancing students' spatial understanding may help students grasp this complex yet fundamental idea. In college level chemistry courses, students with high spatial ability performed better than those considered to have low spatial ability [8]. In addition, high spatial ability has been linked to success in STEM (Science, Technology, Engineering, and Mathematics) in college and beyond. Students who had a strong spatial ability at 13 years old were more likely to earn degrees in STEM and obtain prestigious jobs $[9,10]$. Developing these skills early on can have a lasting impact on a student's education. Prior research has not explored the connection between spatial thinking and the fundamental concept of conservation of matter. This study addresses the link between spatial thinking and understanding of conservation of matter in middle school students through the research question: In what ways do spatial abilities relate to middle school students' understanding of the conservation of matter?

\section{Background Literature}

Many students of all ages find learning chemistry difficult and are often unsuccessful in doing so [11]. One reason is the multiple levels at which chemistry is described. Johnstone $[6,7]$ described this problem; chemistry requires using representations and symbolism to describe matter and its interactions at the macroscopic and sub-microscopic levels. To understand chemistry, a person must be able to simultaneously understand the phenomena with which we can directly interact, and the interactions of particles too small to see. The behavior of these tiny particles explains the macroscopic phenomena we can observe. A person must be able to freely move among this triad of sub-microscopic (i.e., molecular/atomic/subatomic), macroscopic (i.e., what we can easily see with the naked eye), and symbolic (i.e., physical models or drawings of chemical phenomena, symbols, equations) levels of understanding in order to understand chemistry [7]. Chemistry professionals are able to easily slide from area to area in this triad, blending the areas as necessary for a given situation while novices often get stuck on one edge or vertex of this triangle. It is a challenge to work with all three levels at the same time but it is necessary to do so in order to adequately explain and understand chemical phenomena [12,13]. Johnstone [7] illustrates the problem of teaching chemistry to beginners by describing a situation where students are shown three piles of powder: carbon, sulfur, and silicon. Each of these are easily identified as an element to a chemist, but to the novice they are piles of black, yellow, or brown powder. At the macroscopic level, students can see the colored powder, but would have to assume the sub-microscopic level description of the powders is correct. To complicate matters, Johnstone describes adding three more piles: $\mathrm{CuO}$ (copper (II) oxide, a black powder), $\mathrm{PbO} 2$ (lead (IV) oxide, a brown powder), and $\mathrm{PbO}$ (lead (II) oxide, a yellow powder). Again, the novice can perceive the macroscopic appearance, but would have to trust the chemist that these powders are compounds rather than elements as before. Johnstone [7] notes that in "trying to 'sell' the concepts of element and compound, we are simultaneously having to 'sell' the sub micro concepts of atom and molecule and representing all of this by symbols, formulas, and equations. We are in the middle of the triangle ... and few of our students follow us there" easily (p. 704).

Another reason students find learning chemistry challenging is that they fail to understand fundamental concepts in chemistry leaving them unable to understand more advanced concepts that build on these basic ideas as a result [14]. Conservation of matter is a fundamental concept that students must know. The Law of Conservation of Matter states that matter is neither created nor destroyed; the atoms in the reactants are rearranged to form the products [4]. Thus, the mass in a closed system must be the same for the reactants as it is for the products. It is a fundamental law in science and understanding this principle is important for understanding chemistry [15]. Students will see this concept many times throughout their STEM education and are expected to apply this concept to various phenomena. In addition to middle school chemistry, conservation of matter is prevalent in biology. For instance, students must understand conservation of matter in 
order to understand how atoms in the reactants of photosynthesis (carbon dioxide and water) rearrange to form the products (glucose and oxygen); atoms are neither created nor destroyed. It is thus important to teach this concept to students to help them be successful in understanding STEM content.

Unfortunately, this concept is often difficult for students of all ages to master [16]. It requires higher level thinking skills and reasoning. Molecules and atoms are an abstract concept and they cannot be easily observed in the science classroom. One problem is that students often use their prior knowledge and what they see to explain a phenomenon [5]. For example, Piaget and Inhelder [17] found that when younger children were asked to predict what would happen to the mass of water if sugar was added and then dissolved, they predicted that the mass would not change (as cited in [4]). Students did not think that the sugar contributed to the total mass of the substance since it dissolved; they incorrectly assumed that it had "disappeared" since they could no longer see the sugar. Their previous knowledge and lack of reasoning hindered their ability to understand this important concept. Another challenge for middle school students is their fragmented, rather than coherent, explanatory frameworks of understanding of science [18]. As students encounter new information, they struggle to make appropriate connections to build a coherent understanding framework because there are gaps in their prior conceptual understanding of related phenomena.

Misconceptions are prevalent in high school students as well. Özmen and Ayas [4] observed that about half of students in the tenth grade, from Turkey, still struggled to apply the conservation of matter principle to problems and held many misconceptions even after receiving instruction. Common misconceptions included: "a solid is heavier than a gas" and "when a chemical combustion happens in a closed system, the total mass decreases" [4]. Traditional methods of teaching conservation of matter fail to address the common misconceptions students hold, suggesting that the current method of instruction is not effective [5]. The students are failing to assimilate new knowledge into their current knowledge base, and are instead using their intuition and prior knowledge alone to solve problems concerning conservation of matter. Educators have to be aware of students' prior knowledge because it will conflict with their learning of conservation of matter.

Lohman [19] defined spatial ability as "the ability to generate, retain, and manipulate abstract visual images" (as cited in [4], p. 352). Spatial ability is an important skill in the science classroom, particularly in chemistry. Strong spatial ability is not only helpful in understanding chemistry, these skills are transferable to a variety of subjects, such as biology, math, and even art [9,20]. Developing spatial ability would help middle school students in the performance expectation, "develop and use a model to describe how the total number of atoms does not change in a chemical reaction and thus mass is conserved," because they would be able to mentally picture the atoms and how they rearrange in space [3]. Students who have low spatial skills would probably find the task of mentally picturing the atoms and how they rearrange difficult. In one study, college students who had a high spatial ability consistently performed better on various chemistry tasks compared to students classified as having low spatial ability [8]. Developing these skills early on is important to a student's STEM education. Research has shown that students that develop this ability early on are likely to succeed in STEM [9]. Failing to develop these skills could create obstacles for students, ultimately leading to them deciding to not seek a career in STEM.

Contrary to some beliefs, spatial abilities can be improved through intervention. Sorby [21] showed in her study that you can develop the spatial skills of students through practice; this skill is not a fixed, innate ability. Giving students visual tools that they can manipulate can help them develop their spatial skills [21]. Newcombe [22] suggested that educators can improve the spatial skills of their students through two strategies: by directly developing spatial skills through activities designed for the particular age group in question or by incorporating spatial skills into the curriculum, such as the use of visual and symbolic systems. For adolescents and adults, Newcombe [22] suggested that spatially-oriented 
curriculum and direct spatial training is the most beneficial. This includes spoken and written language, diagrams, maps, sketches, gestures, and graphs. In chemistry, this could include students sketching diagrams of the chemical system under consideration or using gesture to relate spatially important pieces of the phenomenon. Unfortunately, students often believe that spatial skills are determined by genetics, which can have a negative impact on their experience with STEM [21]. This phenomenon is particularly seen in female students, which may contribute to their decision to not pursue a career in STEM [21]. One reason students may feel this way is that educators fail to develop this skill, leaving students to figure it out on their own [23]. It is imperative that educators develop the spatial skills of their students to help them feel more confident in STEM, which may lead to them feeling more confident to pursue a career in STEM.

Strengthening students' spatial abilities can help them develop a better understanding of conservation of matter. Middle school students struggle to understand chemistry at the particulate level (sub-microscopic level in Johnstone's terms [7]), which prevents them from understanding the idea that atoms can rearrange in chemical reactions [24]. Educators can help students understand conservation of matter at the particulate level by strengthening their spatial skills. In one study, students that were given computer materials and/or a ball and stick model understood abstract chemistry concepts more and were more likely to retain knowledge of organic molecular structures [25]. Educators can use 3-D visual tools to help develop students' knowledge of conservation of matter at the particulate level. In addition, drawing regular connections to the particulate level and the symbolic level can help students understand how atoms are rearranging in observable phenomenon [4] (pg. 358). Making the material more relevant to the students' lives can help resolve misconceptions [2]. It is important that the content is made relevant to students so that they can assimilate their knowledge of conservation of matter at the particulate level in their explanations of observable phenomena.

Spatial ability has also been shown to help students with problem-solving skills in chemistry $[8,26,27]$. In organic chemistry, students with stronger spatial skills performed better on questions that required problem-solving skills [28]. Students with strong spatial skills are likely better at problem-solving because they represent complex ideas with diagrams and images [1] (p. 477). Developing the students' spatial skills can help them solve problems regarding conservation of matter that require them to apply the concept to novel situations.

\section{Materials and Methods}

This study included seventh-grade students who completed the Conservation of Matter Assessment (CoMA; [29]) and the Purdue Spatial Visualization Test of Rotations (PSVT; [26]) prior to and after receiving chemistry instruction that included lessons on conservation of matter. Students $(\mathrm{N}=388)$ were drawn from seven teachers' classrooms in three schools in the south east central United States. After collection, the data was analyzed for statistical significance and then individual students and individual responses were examined further. This study addresses the research question: In what ways do spatial abilities relate to middle school students' understanding of the conservation of matter?

The three schools were public middle schools located in two neighboring school districts. Student demographics for the schools are in Table 1. Schools A and B are in one district, while School C is in a neighboring district. There were three teachers at School A and two teachers at each of the other schools. Teachers had 2-19 years of teaching experience; all were licensed to teach middle school science. All of these schools use the NGSS middle school science standards following the integrated science model for how the standards are distributed across grades. In this model, students learn about chemistry in both sixth and seventh grade but not eighth grade. In sixth grade, the focus is on the structure of the atom, molecules, and the nature of matter. In seventh grade, the standards focus on chemical reactions, thermochemistry, and conservation of matter. Teachers in this study used the Chemical Reactions Engineered to Address Thermal Energy 
Situations (CREATES) unit as their seventh-grade chemistry unit [30]. This unit includes six lessons and two projects to explore chemical reactions and thermochemistry topics. The unit employs a project-based framework around the question, "How can I use chemical reactions to keep me comfortable?" [30] (p. 113). Students learn about reactants and products in a chemical reaction and how the atoms may rearrange and conserve the mass during a chemical reaction in lesson 3 . Then, in lesson 4 , students further explore the conservation of matter by observing chemical and physical changes and drawing them at the macroscopic and particulate levels. Afterwards, they learn about Antoine Lavoisier and his work on the conservation of matter. Students are presented with four scenarios and asked to choose and test the one they think will confirm the conservation of matter. Then, they discuss their results as a class and determine which scenario was best and why. They complete the lesson by writing a letter explaining what they learned about. Traditionally, the Law of Conservation of Matter is often defined and students are left to understand how to apply it themselves. In CREATES, conservation of matter is explicitly taught by discussing what it means as well as applying it in context. The unit includes an engineering design project that involves creating a hot pack or cold pack. Students need to apply what they learned to design and produce a functional hot pack or cold pack. The end of the unit wraps up with the completion and sharing of student-designed projects that address the driving question. Throughout the unit, teachers ask students to draw and explain what is happening within each lesson. These drawings include both the macroscopic (i.e., what can be observed with the naked eye) and the particulate (i.e., what is happening at the atomic or molecular levels that we cannot directly observe) levels, making a connection between what we see and where the chemistry is happening. These drawings provide opportunities to incorporate spatial thinking training as promoted by Newcombe [22] in addition to addressing the challenges of the multiple levels of chemistry as noted by Johnstone [6,7]. Teachers received a week of professional development (PD) in the summer prior to teaching the unit. The PD included having the teachers experience the unit as learners as well as instruction on how and why the lessons were designed as they were. The teachers also learned about the project-based framework and why incorporating spatial experiences was important, including making explicit connections between the macroscopic and sub-microscopic levels through drawings and explanations when possible throughout the unit.

Table 1. Student Demographics.

\begin{tabular}{cccccc}
\hline & White & Hispanic or Latino & African American & Other & Economically Disadvantaged \\
\hline A & $69.1 \%$ & $9.4 \%$ & $8.7 \%$ & $12.8 \%$ & $41.2 \%$ \\
B & $56.3 \%$ & $12.3 \%$ & $20.8 \%$ & $10.6 \%$ & $53.3 \%$ \\
C & $68.1 \%$ & $8.9 \%$ & $13.9 \%$ & $9.1 \%$ & $60.0 \%$ \\
\hline
\end{tabular}

The Conservation of Matter Assessment (CoMA; [29]) is a ten-item instrument that measures students' understanding of the conservation of matter. Four of the questions on this assessment are open-ended; a rubric (see Appendix A) was adapted from the Conservation of Matter Assessment Manual [29] that considered both whether the student was able to correctly identify if the mass should change as well as the reasoning given. In order to receive the highest score on a question (4 points), the student needed to both identify the change (or lack of) in mass as well as provide a thorough explanation. The CoMA questions consist of a question asking for the change in mass (more, less, same) after an action paired with a question asking students to explain their reasoning for the previous response. There are four pairs of questions followed by two multiple choice questions. The mass and explanation pairs were each scored using rubrics with a total of 4 points possible for each pair. The multiple-choice questions were scored either correct or incorrect for one point possible on each. The CoMA had a total of 18 possible points. Two chemistry teachers scored the CoMA responses independently using the rubric, discussing a subset of the scores to establish interrater reliability. Upon initial scoring, the two raters agreed 
on $75 \%$ of the scores. After discussion, this rose to $100 \%$ as differences in scoring were identified; the scorers rescored discrepant cases as needed to come to an agreement.

The Purdue Spatial Visualization Test of Rotations (PSVT; [26]) is a 20-question assessment of the mental rotation ability of students. Each question provides an analogy for students to apply; a block is shown rotated, and students are asked to choose a block that illustrates how a new block would look if rotated in the same manner as the first pair. The PSVT was scored as correct/incorrect for each question, giving a total of 20 possible points; student scores are reported here as percentage correct.

Spearman's Correlations and Sign tests were conducted to examine the relationship between students' spatial thinking (specifically, mental rotation ability) and understanding of conservation of matter. Spearman's Rho was used over Pearson's correlation as the data was non-normally distributed. Similarly, a sign test was chosen over a parametric test to observe whether there were significant pre- to post-assessment changes in students' performance. In addition to these quantitative, statistical tests, individual student responses were also examined. First, the results are presented for three example students (see Tables 2 and 3). These example students were chosen as they scored very low (Anna, $5 \%$ or one question correct), in the middle (Katie, $45 \%$ or 9 questions correct), or very high (Sam, 90\% or 18 questions correct) on the PSVT prior to instruction. While all three students received perfect scores on the final CoMA, their PSVT scores continued to vary. Second, additional example student responses to illustrate the rubric scores are shown in Table 4.

Table 2. Example student scores on PSVT and CoMA.

\begin{tabular}{ccccc}
\hline Student & $\begin{array}{c}\text { PSVT } \\
\text { Pre-Assessment }\end{array}$ & $\begin{array}{c}\text { CoMA } \\
\text { Pre-Assessment } \\
\text { (18 Possible) }\end{array}$ & $\begin{array}{c}\text { PSVT } \\
\text { Post-Assessment }\end{array}$ & $\begin{array}{c}\text { CoMA } \\
\text { Post-Assessment } \\
\text { (18 Possible) }\end{array}$ \\
\hline Anna & $5 \%$ & 9 & $50 \%$ & 18 \\
Katie & $45 \%$ & 4 & $45 \%$ & 18 \\
Sam & $90 \%$ & 12 & $80 \%$ & 18 \\
\hline
\end{tabular}

Table 3. Example student responses on CoMA, varied by spatial ability.

\begin{tabular}{|c|c|c|c|c|}
\hline & \multicolumn{2}{|c|}{ Prior to Intervention } & \multicolumn{2}{|c|}{ Post-Intervention } \\
\hline & Atoms & Mass & Atoms & Mass \\
\hline Anna & $\begin{array}{l}\text { More atoms in the bag after } \\
\text { the reaction because "the } \\
\text { bag expanded meaning } \\
\text { there is more" than before. }\end{array}$ & "It expanded." & $\begin{array}{l}\text { Number of atoms would } \\
\text { be the same after mixing } \\
\text { the substances because } \\
\text { "matter is not created } \\
\text { or destroyed." }\end{array}$ & $\begin{array}{l}\text { Mass would be the same } \\
\text { because "atoms weigh } \\
\text { the same." }\end{array}$ \\
\hline Katie & $\begin{array}{l}\text { Number of atoms would } \\
\text { increase after mixing the } \\
\text { substances because "when } \\
\text { objects mix with atoms the } \\
\text { more atoms they are going } \\
\text { to have." }\end{array}$ & $\begin{array}{l}\text { Mass would decrease } \\
\text { because "when objects } \\
\text { come together and atoms } \\
\text { combine the less mass they } \\
\text { will have." }\end{array}$ & $\begin{array}{l}\text { Number of atoms does not } \\
\text { change after mixing } \\
\text { substances "since it was a } \\
\text { closed system, no matter } \\
\text { could get in or leave." }\end{array}$ & $\begin{array}{l}\text { Mass does not change after } \\
\text { mixing substances because } \\
\text { "In the conservation of } \\
\text { mass, it states that mass is } \\
\text { not created or destroyed in } \\
\text { a closed system." }\end{array}$ \\
\hline Sam & $\begin{array}{l}\text { Number of atoms would } \\
\text { stay the same because } \\
\text { "there is still the same } \\
\text { amount because they were } \\
\text { just mixed." }\end{array}$ & $\begin{array}{l}\text { Mass would decrease after } \\
\text { the substances mixed } \\
\text { because "some of the } \\
\text { atoms turned to gas." }\end{array}$ & $\begin{array}{l}\text { Number of atoms wouldn't } \\
\text { change because "the } \\
\text { atoms are not created } \\
\text { neither destroyed" }\end{array}$ & $\begin{array}{l}\text { Mass would not change } \\
\text { because "the atoms are not } \\
\text { created neither destroyed." }\end{array}$ \\
\hline
\end{tabular}


Table 4. Representative student responses on CoMA rubric.

\begin{tabular}{|c|c|c|c|}
\hline Score & $\mathrm{S} / \mathrm{M} / \mathrm{L}$ & Atoms Responses & Mass Responses \\
\hline 4 & Same (S) & $\begin{array}{l}\text { "in a closed system matter can't escape or } \\
\text { come in so it's the same." } \\
\text { "It is the same since atoms cannot get into or } \\
\text { out of the bag." } \\
\text { "There would be the same amount of atoms, } \\
\text { even though they would be moving more } \\
\text { freely as a gas." } \\
\text { "The atoms would be the same because in } \\
\text { matter atoms are not created or destroyed." }\end{array}$ & $\begin{array}{l}\text { "Atoms make up all matter. Matter has } \\
\text { weight. Again, because of the closed } \\
\text { system, no atoms can get in or out." } \\
\text { "It's the same because all you are doing is } \\
\text { mixing the two item and not adding } \\
\text { anything to change the mass." } \\
\text { "The total mass would be the same because } \\
\text { the perfume atoms are still the same." } \\
\text { "Mass cannot be created nor destroyed." }\end{array}$ \\
\hline 3 & Same (S) & $\begin{array}{l}\text { "Because the baking soda and orange juice } \\
\text { can't make more atoms" } \\
\text { "atoms were moved to the bubbles" }\end{array}$ & $\begin{array}{l}\text { "it's still the same perfume." } \\
\text { "it's just mixed" } \\
\text { "the bag stays the same" }\end{array}$ \\
\hline 2 & More $(\mathrm{M})$ or Less $(\mathrm{L})$ & $\begin{array}{l}\text { "because when you mixed things together } \\
\text { you are going to have more atoms then you } \\
\text { started out with" } \\
\text { "another substance was made" } \\
\text { "gas is being released" }\end{array}$ & $\begin{array}{l}\text { "gasses have less mass than liquids" } \\
\text { "most of the molecules evaporated with the } \\
\text { elements of the perfume" }\end{array}$ \\
\hline 1 & More $(\mathrm{M})$ or Less $(\mathrm{L})$ & $\begin{array}{l}\text { "it has more because the matter spaced the } \\
\text { atoms apart" } \\
\text { "because you can see the bubble" } \\
\text { "the orange juice and baking soda mixed so } \\
\text { some of the baking soda dissolved" } \\
\text { "The perfume disappeared." } \\
\text { "I answered less because the liquid perfume } \\
\text { has more atoms than gas." }\end{array}$ & $\begin{array}{l}\text { "forming new substance" } \\
\text { "she picked up what was left that didn't } \\
\text { turn into a gas" } \\
\text { "because one is a liquid and one is a gas" } \\
\text { "because those atoms are still lost in the air } \\
\text { you can't get them back" }\end{array}$ \\
\hline 0 & No Answer & $\begin{array}{l}\text { "because it is" } \\
\text { "less" } \\
\text { "idk" }\end{array}$ & $\begin{array}{l}\text { "I don't know" } \\
\text { "k" } \\
\text { "because" }\end{array}$ \\
\hline
\end{tabular}

\section{Results}

Spearman's correlation was run to determine the relationship between students' spatial reasoning scores (PSVT) and chemistry content knowledge scores (CoMA) prior to and after the students experienced a chemistry unit (CREATES) [30] in 7th grade that included explicit instruction on conservation of matter (See Table 1). A moderate, positive correlation was found between PSVT and CoMA scores both prior to $\left(r_{s}(386)=0.279\right.$, $p<0.01)$ and after the chemistry unit $\left(r_{s}(378)=0.431, p<0.01\right)$. An exact sign test was used to compare the differences in students' pre- and post-instruction assessment scores on the CoMA and the PSVT. Students' median post-assessment scores were significantly better than pre-assessment scores for both the overall CoMA (difference: $2.00 ; p=0.000$ ) and the PSVT (difference: $4.73 ; p=0.000$ ). Prior to the unit, the mean score on the PSVT was $36.92 \%$, which rose to $41.33 \%$ after instruction. The median score on the CoMA prior to instruction was 10 and after instruction was 12; the range of scores was from 0 (all incorrect) to 18 (all correct) in both cases.

One CoMA question asked about mixing orange juice and baking soda in a closed, zip-top bag. Students were expected to state whether there were the same, more, or less atoms in the bag and then to explain their response. The next question asked whether there were the same, more, or less mass in the bag after the substances were mixed. See Tables 3 and 4 for example student responses. One student (Anna) on the pre-assessment responded to the first question saying that there were more atoms in the bag after the reaction because "the bag expanded meaning there is more" than before. Anna justified her response of more mass by simply saying "it expanded." She received scores of 2 and 1 on these questions, respectively. On the post-assessment, Anna said the number of atoms 
would be the same after mixing the substances because "matter is not created or destroyed" and the mass would be the same because "atoms weigh the same." Anna received a score of 4 on both questions. Anna received a score of 9 on the pre-assessment and 18 on the post-assessment. Another student (Katie) answered the first question on the pre-assessment by saying the number of atoms would increase after mixing the substances because "when objects mix with atoms the more atoms they are going to have." She also said the mass would decrease because "when objects come together and atoms combine the less mass they will have." Paradoxically, to this student more atoms seemed to equate to less mass. On the post-assessment, Katie responded that neither the number of atoms nor the mass would change after mixing the substances, justifying the consistent number of atoms with "since it was a closed system, no matter could get in or leave" and the consistent mass with "In the conservation of mass, it states that mass is not created or destroyed in a closed system." Katie received an overall score of 4 on the pre-assessment and a score of 18 on the post-assessment. A third student (Sam) scored 16 on the pre-assessment CoMA and 18 on the post-assessment. He said that the number of atoms would stay the same because "there is still the same amount because they were just mixed" but showed a misconception about the mass, saying it would decrease after the substances mixed because "some of the atoms turned to gas." On the post-assessment, Sam said the number of atoms wouldn't change because "the atoms are not created neither destroyed," and the mass would not change because "the atoms are not created neither destroyed." Sam scored 12 on the pre-assessment and 18 on the post-assessment CoMA. Prior to the chemistry unit, Anna scored 5\% on the PSVT, Katie scored $45 \%$, and Sam scored $90 \%$. After instruction, Anna improved to 50\% on the PSVT, Katie stayed at $45 \%$, and Sam's score was $80 \%$.

\section{Discussion}

This study examined the connection between spatial ability and student understanding of the fundamental chemistry concept of conservation of matter. This study adds to the body of literature on spatial thinking in chemistry in that it highlights the relationship between understanding chemistry and spatial ability at the middle school level. Previous research has shown students with higher spatial ability perform better in college-level chemistry, but little research has been done at the middle school level [8]. Wu and Shah [1] called for more work to be done examining the relationship between visuospatial thinking and understanding chemistry at the pre-college level. Middle school is an important time of transition, where chemistry is addressed from a particulate view rather than the macroscopic view on which the elementary standards are based [31]. Additionally, the NGSS introduces fundamental ideas in chemistry such as conservation of matter, thermochemistry, and the particulate nature of matter at the middle level [3]. Middle school is also an important time for considering the role of spatial reasoning in understanding content because preteens undergo a second wave of brain development in the area of spatial reasoning, placing them at an ideal age for improving spatial reasoning [32]. In addition, novices rely more on decontextualized spatial abilities than experts do, making spatial reasoning potentially more important at earlier ages than for students later into their studies in chemistry [33].

It is important to develop the spatial skills of students to help them understand complex concepts in chemistry, especially at the particulate level. In this study, the positive correlation between the PSVT and CoMA scores increased significantly after direct intervention. Prior to intervention, students struggled to understand that molecules rearrange in chemical reactions and that matter is conserved in a closed system. For example, Anna thought that the number of atoms would increase if you mixed orange juice and baking soda in a closed bag. Strengthening students' spatial skills likely helped them be able to better visualize how atoms rearrange in chemical reactions. After intervention, Anna's PSVT score increased from 5\% to 50\% and her CoMA score increased from a 9 to an 18. When presented with the same problem regarding mixing orange juice and baking soda in a closed bag, she answered that the number of atoms would be the same after mix- 
ing the substances because "matter is not created or destroyed." In addition, the students understood the concept of a closed system better. For example, Katie stated "since it was a closed system, no matter could get in or leave." Strengthening the students' spatial ability may have helped them better understand the conservation of mass because the students could visualize the atoms and how they were interacting. In both the questions about atoms and mass being conserved, we see students better making the connection between the macroscopic phenomenon they can observe and the sub-microscopic or particulate level where the chemistry is happening which Johnstone highlighted as an important skill in order to understand chemistry [6,7].

The results from the individual questions on the CoMA also show that students with lower spatial ability had less accurate and/or less complete explanations for the conservation of matter after substances were mixed than students with higher spatial abilities. Students with lower spatial abilities often provided nonsensical or irrelevant explanations, if they offered any at all. Some said things like "it would bubble up then dissolve" or "yes, because they can be taken apart" or simply "it mixed." Other students would simply state "Law of Conservation of Mass" with no further explanation. Students that have lower spatial abilities tend to depend on their observations and prior knowledge [5]. None of these responses address why the mass or number of atoms would remain constant. Samarapungavan and Wiers [18] found that middle school students tended to have fragmented rather than coherent explanatory frameworks of understanding of science. This is evidenced by the students who were able to provide partial answers but not fully explain them. They may still be making connections to the conservation of matter within their explanatory framework.

The CREATES unit may have helped to improve the spatial ability of the students in addition to improving their understanding of conservation of matter, though the improvement in spatial ability may also have been caused by other factors such as maturation of students, instruction in other courses, or the improvement could have been coincidental. The lessons in CREATES frequently make connections to the particulate nature of matter [30]. Making frequent connections from the particulate view to the macroscopic view can help students better understand the science behind observable phenomenon [4]. As Johnstone [6,7] noted, novices in chemistry often get stuck on one vertex of the chemistry triad. In our study, many students seemed to be stuck on the macroscopic views of matter, having difficulty in connecting it to the particulate level. While they could respond to questions about what happened to the atoms and the mass in each of the situations, many did not make the connection in their explanations. Looking at the example responses in Table 4 , students who scored a 4 on the mass open response questions often included both mass and atoms in their explanation for why the mass did not change. However, for lower-scored responses, the answers students provided were both increasingly vague as the scores decreased and less likely to refer to atoms. In looking at the example students on Table 3, the student with the lowest spatial scores on the pre-assessment simply said "it expanded" without mentioning mass or atoms. On her post-assessment, she mentioned both atoms and weight. Her response about atoms was also less vague after instruction than prior to instruction. While Katie (the mid-spatial score) did not mention atoms in her response about mass after instruction, Sam (highest spatial scores) provided a succinct explanation that mentioned the atoms as the reason for the mass not changing. In terms of the chemistry triad [6,7], Sam's responses suggest he is able to make connections between the macroscopic and sub-microscopic (or particulate) levels of matter. Sam was able to do this both prior to and after instruction, though his responses suggested he incorporated the definition of the Law of Conservation of Matter into his explanatory schema. Anna was also to make this macroscopic-particulate connection after instruction. Her explanations also improved in general; her spatial scores (5\% to $50 \%$ ) paralleled this change. Katie, however, did not show a similar change. Her responses prior to instruction mentioned both atoms and mass, but did not make the connection that mass was conserved because 
the atoms were conserved. Her post-instruction response did not mention atoms at all, though she did mention the definition of the Law of Conservation of Matter.

Even prior to any intervention, there was a positive correlation between the PSVT and the CoMA; students who performed better on the PSVT were more likely to perform better on the CoMA. This is similar to what Carter et al. [8] found in their study; college students that performed better on spatial ability tests were more likely to perform better on general chemistry exams. Not only do spatial skills help students understand concepts at the particulate level, spatial skills make it easier for students to understand complex problems [8]. Carter found that students labeled as having a strong spatial ability performed better on tasks that required spatial skills, such as predicting structures of ionic solids, and tasks that were not necessarily spatial in nature, such as stoichiometry problems [8]. It is likely that students with stronger spatial skills are better able to "disembed and restructure information" to understand complex problems [8] (p. 2). In this study, it is likely that the student Sam performed better on the CoMA prior to any instruction because he had better problem-solving skills, which is suggested by his high initial PSVT score (90\%).

The concept of conservation of matter is fundamental to understanding chemistry [15]. Unfortunately, many students struggle with this concept [16]. Developing the spatial skills of students may help further their understanding of the concept of conservation of matter. Understanding the fundamental concepts in chemistry, such as conservation of matter, is essential for building understanding of future topics [13]. In the schools in which this data was collected, chemistry is taught in 6th and 7th grade, but not 8th grade. The students in this sample will not formally receive chemistry instruction again until high school, though they will see applications of chemistry concepts in other science courses. For instance, when learning about any of the myriad topics in a biology course, students need to be able to apply an understanding of the Law of Conservation of Mass. The human body relies on a number of chemical reactions to function. The molecules in food that we consume are broken down into smaller pieces through chemical reactions. Pieces of these food molecules and/or individual atoms are used to store energy as different molecules or are used in building structures in the body. Some are expelled as waste. Regardless of what happens to the original molecules, none of the atoms or the mass of those atoms is destroyed. While students may be able to memorize the Law of Conservation of Mass and be able to share that matter is neither created nor destroyed, they need to understand what that means in order to apply the concept, both within chemistry and within other courses.

\subsection{Limitations and Future Research}

A potential limitation to this study is that although all teachers used the same CREATES lessons, there may have been variations in how the information was taught to the students. We also do not have information on how exactly the lessons on conservation of matter were taught in the classroom. We know how the lesson was designed, but teachers adapt lessons to fit their classrooms and students. This information could provide insight into why students responded the way they did. For instance, did the teachers make explicit connections between the macroscopic and sub-microscopic levels as was intended? Did they make connections between the conservation of mass (i.e., the macroscopic view) and the conservation of atoms (i.e., the sub-microscopic view) in the lessons?

Overall, significant, positive correlations were found between students' performance on a mental rotation assessment (PSVT) and an assessment of their understanding of conservation of matter (CoMA). While we cannot infer any causal relationships, this data shows the two are related. Future research should further investigate this link and why the two are related. One possible avenue of investigation would be to consider interviewing students further on the connection between atoms and mass being conserved. It would also be helpful to know more about how teachers are talking about chemistry in the classroom in terms of the chemistry triad [6,7]. Future research should also investigate teachers' understanding of conservation of matter as well as their spatial awareness and skills. 


\subsection{Implications for Teachers}

The concept of conservation of matter in chemistry is fundamental to understanding chemistry [15]. Unfortunately, many students struggle with this concept [16]. We observed a significant increase in the median scores between the pre- and post-assessments, highlighting the importance of developing the spatial ability of students in chemistry; developing the spatial skills of students may help further their understanding of the concept of conservation of matter. Understanding the fundamental concepts in chemistry, such as the conservation of matter, are essential for building understanding of future topics [13]. In the schools in which this data was collected, chemistry is taught in 6th and 7th grade, but not 8 th grade. The students in this sample will not receive formal chemistry instruction again until high school, though they will see applications of chemistry concepts in other science courses. For instance, when learning about any of the myriad topics in a biology course, students need to be able to apply an understanding of the Law of Conservation of Mass. The human body relies on a number of chemical reactions to function. The molecules in food that we consume are broken down into smaller pieces through chemical reactions. Pieces of these food molecules and/or individual atoms are used to store energy as different molecules or are used in building structures in the body. Some are expelled as waste. Regardless of what happens to the original molecules, none of the atoms or the mass of those atoms is destroyed. While students may be able to memorize the Law of Conservation of Mass and be able to share that matter is neither created nor destroyed, they need to understand what that means in order to apply the concept, both within chemistry and within other courses.

Educators have to be aware of the many misconceptions students have regarding the conservation of matter, as highlighted in this study. Educators should also assess their students' prior knowledge of conservation of matter instead of assuming they already understand it. Students with rudimentary understanding rely on observations and assume that when a substance dissolves, it simply disappears [17], as cited in [2]. Traditional teaching methods are not addressing these concerns, as shown by the continuation of misconceptions into high school [2]. Educators need to address these concerns, instead of assuming students have this base knowledge. Instruction should explicitly develop understanding of the particulate nature of matter through strengthening spatial ability. One way to do this is through the use of visual tools; Copolo and Hounshell [25] found that students who used computer materials and ball and stick models were better able to grasp complex chemistry topics. Educators do not need to buy expensive software to help develop students' understanding of the particulate nature of matter. In the CREATES lesson, many items used, such as orange juice and baking soda, can be purchased at a local grocery store [30]. Being aware of misconceptions and addressing them will help educators teach conservation of matter more effectively. This is important because, as stated previously, conservation of matter shows up in higher levels of chemistry and in many different subjects, such as biology $[9,20,21]$.

It is also important to make the material relevant for the students [2]. The CREATES unit does this by surrounding the activities around natural phenomena. For instance, in lesson 2, they learn about physical and chemical changes in the context of making cookies; in lesson 6, students have to explain how cold packs work and design their own cold packs [30]. The CREATES lessons also employ spatially rich, hands-on activities. Tools that the students can manipulate, such as blocks, help strengthen students' spatial ability [21]. Lesson 5 introduces the idea that atoms combine in constant ratios to make molecules with the use of blocks [30]. It is important for educators to incorporate spatial skills into curriculum, such as models, graphs, etc., to effectively develop the spatial ability of their students [22]. In addition, specific, explicit connections need to be made to the levels of chemistry Johnstone [6,7] mentioned; students cannot be expected to develop a facility with moving among the areas of the chemistry triad on their own. The connections between areas of the triad should be made explicit in the classroom as in CREATES where students were asked to draw and explain both the macroscopic and sub-microscopic views. 
These types of activities could be a reason that students were able to improve their spatial thinking skills along with their understanding of conservation of matter.

\section{Conclusions}

This study highlights the importance of developing middle schoolers' spatial skills. Students with stronger spatial skills, as measured by the PSVT, performed better on the CoMA. We can only imply correlation, not causation, suggesting that more research needs to be done in this area. Previous research has shown that there is a correlation between spatial ability and higher levels of chemistry, such as organic chemistry, but little research has been done to show the importance of spatial ability at the pre-college level. A recent literature review by Oliver-Hoyo and Babilonia-Rosa [34] in the Journal of Chemical Education has focused on the development of spatial skills at the college level. Why wait until then? Wai, Lubinski, and Benbow [9] found that students who later earned STEM degrees had significantly higher spatial abilities at age 13 than those who earned degrees in other areas. Also, higher level achievements (e.g., earning a PhD vs. a BS) are predicted by greater spatial ability [10]. More research needs to be done earlier in a child's education, since spatial skills are needed as early as middle school, where conservation of matter is first introduced.

Perhaps one of the reasons students struggle to develop coherent frameworks of science understanding is the lack of development of spatial thinking. Also, middle school students struggle to understand chemistry at the particulate level [24]. Spatial thinking can help students understand that molecules rearrange in space during a chemical reaction, and are thus conserved. As a science education community, we need to be thinking about how to create and encourage spatially rich experiences in our classrooms to promote both the understanding of science and the development of spatial ability. Many educators do not explicitly develop spatial skills, leaving students to figure it out on their own [23]. Hegarty [35] commented that the lack of emphasis on spatial thinking in schools is preventing "less able students from achievement in science" (p. 143). Failure to develop spatial skills can be particularly harmful to female students. Other studies have found gender differences in spatial thinking $[8,18,21,22]$. While no gender differences were found in this study, these should be considered in future work on this topic.

Author Contributions: Conceptualization, M.C. and J.W.; methodology, M.C., C.F., and H.F.; formal analysis, M.C., C.F., and H.F.; resources, J.W. and M.C.; data curation, M.C.; writing-original draft preparation, M.C. and B.M.-M.V.; writing-review and editing, M.C. and J.W.; supervision, J.W. All authors have read and agreed to the published version of the manuscript.

Funding: This research received no external funding.

Institutional Review Board Statement: The study was conducted according to the guidelines of the Declaration of Helsinki, and approved by the Institutional Review Board of University of Kentucky (protocol code 45148).

Informed Consent Statement: Informed consent was obtained from all subjects involved in the study.

Conflicts of Interest: The authors declare no conflict of interest. 


\section{Appendix A}

Table A1. Scoring rubric for number of atoms questions on the CoMA.

\begin{tabular}{|c|c|c|}
\hline Score Given & $\mathrm{S} / \mathrm{M} / \mathrm{L}$ & Explanation \\
\hline 4 & Same (S) & $\begin{array}{c}\text { Student writes about: } \\
\text { Nothing Changes } \\
\text { Same amount } \\
\text { Matter not being created or destroyed } \\
\text { Nothing can get in or out of the bag (Jeff's Task) } \\
\text { Atoms are rearranged } \\
\text { States "law of conservation of matter" }\end{array}$ \\
\hline 3 & Same (S) & $\begin{array}{l}\text { Student's response does not include what is stated } \\
\text { above or insufficient explanation or No evidence of } \\
\text { reasoning about the task }\end{array}$ \\
\hline 2 & More $(\mathrm{M})$ or Less $(\mathrm{L})$ & $\begin{array}{c}\text { Student writes about: } \\
\text { Atoms getting in the bag } \\
\text { Atoms being created } \\
\text { New substance (Jeff's Task) } \\
\text { Or } \\
\text { Adding two groups of atoms makes more atoms } \\
\text { Atoms disappear, are destroyed or evaporate } \\
\text { Atoms stay on the ground }\end{array}$ \\
\hline 1 & More $(\mathrm{M})$ or Less $(\mathrm{L})$ & $\begin{array}{l}\text { Insufficient explanation or No evidence of reasoning } \\
\text { about the task }\end{array}$ \\
\hline 0 & No Answer & Blank/No evidence of reasoning about the task \\
\hline
\end{tabular}

Table A2. Scoring rubric for mass of atoms questions on the CoMA.

\begin{tabular}{|c|c|c|}
\hline Score Given & $\mathrm{S} / \mathrm{M} / \mathrm{L}$ & Explanation \\
\hline 4 & Same (S) & $\begin{array}{c}\text { Student writes about: } \\
\text { Nothing Changes } \\
\text { Same amount } \\
\text { Matter not being created or destroyed } \\
\text { Nothing can get in or out of the bag (Jeff's Task) } \\
\text { Atoms are rearranged } \\
\text { States "law of conservation of matter" }\end{array}$ \\
\hline 3 & Same (S) & $\begin{array}{l}\text { Student's response does not include what is stated } \\
\text { above or insufficient explanation or no evidence of } \\
\text { reasoning about the task }\end{array}$ \\
\hline 2 & More $(\mathrm{M})$ or Less $(\mathrm{L})$ & $\begin{array}{c}\text { Student writes about: } \\
\text { Atoms getting in the bag } \\
\text { Atoms being created } \\
\text { More mass because atoms expanded } \\
\text { Liquids and wet substances weigh more } \\
\text { Greater volume, greater mass } \\
\text { Or } \\
\text { Atoms disappear, are destroyed or evaporate } \\
\text { Gases weighing less } \\
\text { Gases have no mass } \\
\text { Atoms get smaller and weigh less } \\
\text { Atoms getting lighter and weighing less }\end{array}$ \\
\hline 1 & More $(\mathrm{M})$ or Less (L) & $\begin{array}{l}\text { Insufficient explanation or no evidence of reasoning } \\
\text { about the task }\end{array}$ \\
\hline 0 & No Answer & Blank/No evidence of reasoning about the task \\
\hline
\end{tabular}




\section{References}

1. Wu, H.; Shah, P. Exploring visuospatial thinking in chemistry learning. Sci. Educ. 2004, 88, 465-492. [CrossRef]

2. Özmen, H.; Ayas, A. Students' difficulties in understanding the conservation of matter in open and closed-system chemical reactions. Chem. Educ. Res. Pract. 2003, 4, 279-290. [CrossRef]

3. NGSS Lead States. Next Generation Science Standards: For States, by States; The National Academies Press: Washington, DC, USA, 2013.

4. Harle, M.; Towns, M. A review of spatial ability literature, its connection to chemistry, and implications for instruction. J. Chem. Educ. 2011, 88, 351-360. [CrossRef]

5. Stavy, R. Pupil's problems in understanding conservation of matter. Int. J. Sci. Educ. 1990, 12, 501-512. [CrossRef]

6. Johnstone, A.H. Why is science difficult to learn? Things are seldom what they seem. J. Comput. Assist. Learn. 1991, 7, 75-83. [CrossRef]

7. Johnstone, A.H. The development of chemistry teaching: A changing response to changing demand. J. Chem. Educ. 1993, 70, 701-705. [CrossRef]

8. Carter, C.S.; LaRussa, M.A.; Bodner, G.M. A study of two measures of spatial ability as predictors of success in different levels of general chemistry. J. Res. Sci. Teach. 1987, 24, 645-657. [CrossRef]

9. Wai, J.; Lubinski, D.; Benbow, C.P. Spatial ability for STEM domains: Aligning over 50 years of cumulative psychological knowledge solidifies its importance. J. Educ. Psychol. 2009, 101, 817-835. [CrossRef]

10. Kell, H.J.; Lubinski, D.; Benbow, C.P. Who rises to the top? Early indicators. Psychol. Sci. 2013, 24, 648-659. [CrossRef]

11. Nakhleh, M.B. Why some students don't learn chemistry: Chemical misconceptions. J. Chem. Educ. 1992, 69, 191-196. [CrossRef]

12. Treagust, D.; Chittleborough, G.; Mamiala, T. The role of submicroscopic and symbolic representations in chemical explanations. Int. J. Sci. Educ. 2003, 25, 1353-1368. [CrossRef]

13. Gabel, D.; Samuel, K.; Hunn, D. Understanding the particulate nature of matter. J. Chem. Educ. 1987, 64, 695-697. [CrossRef]

14. Russell, J.W.; Kozma, R.B.; Jones, T.; Wykoff, T.; Marx, N.; Davis, J. Use of simultaneous-synchronized macroscopic, microscopic, and symbolic representations to enhance the teaching and learning of chemical concepts. J. Chem. Educ. 1997, 74, 330-334. [CrossRef]

15. Agung, S.; Schwartz, M.S. Students' understanding of conservation of matter, stoichiometry, and balancing equations in Indonesia. Int. J. Sci. Educ. 2007, 29, 1679-1702. [CrossRef]

16. Paixão, M.F.; Cachapuz, A. Mass conservation in chemical reactions: The development of an innovative teaching strategy based on the history and philosophy of science. Chem. Educ. Res. Pract. 2000, 1, 201-215. [CrossRef]

17. Piaget, J.; Inhelder, B. The Child's Construction of Quantities: Conservation and Atomism; Routledge: London, UK, 1974.

18. Samarapungavan, A.; Wiers, R.W. Children's thoughts on the origin of species: A study of explanatory coherence. Cogn. Sci. 1997, 21, 147-177. [CrossRef]

19. Lohman, D.F. Spatial Ability: A Review and Reanalysis of the Correlational Literature. In Aptitude Research Project; Technical Report No. 8, Aptitude Research Project; Stanford University School of Education: Palo Alto, CA, USA, 1979.

20. Mohler, J.L. Computer graphics education: Where and how do we develop spatial ability? In EG Education Papers; Brown, J., Hansmann, W., Eds.; The Eurographics Association: Geneve, Switzerland, 2006. [CrossRef]

21. Sorby, S.A. Educational research in developing 3-D spatial skills for engineering students. Int. J. Sci. Educ. 2009, 31, 459-480. [CrossRef]

22. Newcombe, N. Harnessing Spatial Thinking to Support Stem Learning; OECD Education Working Papers, No. 161; OECD Publishing: Paris, France, 2017. [CrossRef]

23. Webb, R.M. Spatial ability: A neglected dimension in talent searches for intellectually precocious youth. J. Educ. Psychol. 2007, 99, 397-420. [CrossRef]

24. Ahtee, M.; Varjola, I. Students' understanding of a chemical reaction. Int. J. Sci. Educ. 2007, 20, 305-316. [CrossRef]

25. Copolo, C.; Hounshell, P. Using three-dimensional models to teach molecular structures in high school chemistry. J. Sci. Educ. Technol. 1995, 4, 295-305. [CrossRef]

26. Bodner, G.M.; Guay, R.B. The Purdue visualization of rotations test. Chem. Educ. 1997, 2, 1-17. [CrossRef]

27. Grabow, R. The Relationship of Visual Spatial Ability to Performance in Solving Stoichiometric Problems in a High School Chemistry Class. Ph.D. Thesis, California State University, Fullerton, CA, USA, 2003.

28. Pribyl, J.R.; Bodner, G.M. Spatial ability and its role in organic chemistry: A study of four organic courses. J. Res. Sci. Teach. 1987, 24, 229-240. [CrossRef]

29. Pyke, C.; Ochsendorf, R. Conservation of matter assessment manual. 2004; Unpublished Manuscript.

30. Wilhelm, J.; Wilhelm, R.; Cole, M. Creating Project-Based STEM Environments: The REAL Way; Springer International Publishing: Cham, Switzerland, 2019.

31. Talanquer, V. On cognitive constraints and learning progressions: The case of "structure of matter". Int. J. Sci. Educ. 2008, 31, 2123-2136. [CrossRef]

32. Giedd, J.N.; Blumenthal, J.; Jeffries, N.O.; Rajapakse, J.C.; Vaituzis, A.C.; Liu, H.; Castellanos, F.X. Development of the human corpus callosum during childhood and adolescence: A longitudinal MRI study. Prog. Neuro-Psychopharmacol. Biol. Psychiatry 1999, 23, 571-588. 
33. Uttal, D.H.; Cohen, C.A. Spatial thinking and STEM education: When, why, and how? Psychol. Learn. Motiv. Adv. Res. Theory 2012, 57, 147-181. [CrossRef]

34. Oliver-Hoyo, M.; Babilonia-Rosa, M.A. Promotion of Spatial Skills in Chemistry and Biochemistry Education at the College Level. J. Chem. Educ. 2017, 94, 996-1006. [CrossRef]

35. Hegarty, M. Spatial thinking in undergraduate science education. Spat. Cogn. Comput. 2014, 14, 142-167. [CrossRef] 